\title{
Novel Sigma 1 Receptor Antagonists as Potential Therapeutics for Pain Management
}

Youyi Peng1,*, Qiang Zhang ${ }^{2, \dagger}$, and William J. Welsh ${ }^{1,2, *}$

1: Biomedical Informatics Shared Resource, Cancer Institute of New Jersey, Rutgers, The State University of New Jersey, 195 Little Albany Street, New Brunswick, NJ 08903, United States

2: Department of Pharmacology, Robert Wood Johnson Medical School, Rutgers, The State University of New Jersey, 661 Hoes Lane West, Piscataway, NJ 08854, United States

${ }^{\dagger}$ : Current address: Intra-Cellular Therapies, Inc., 430 East $29^{\text {th }}$ Street, Suite 900, New York, NY 10016, United States

*: Corresponding authors, pengyo@,cinj.rutgers.edu, welshwj@,rwjms.rutgers.edu. 


\section{Table of Contents}

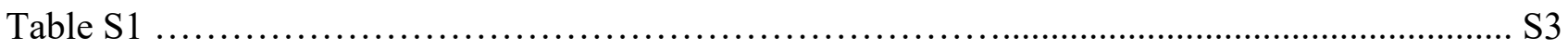

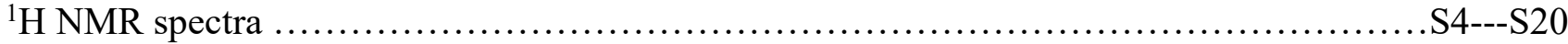

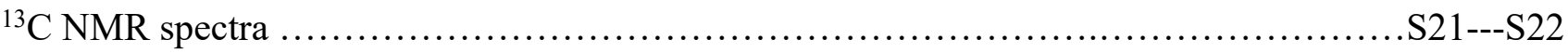

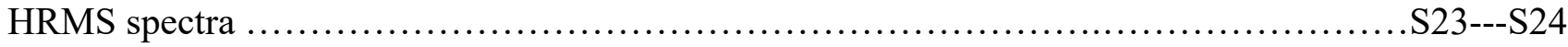

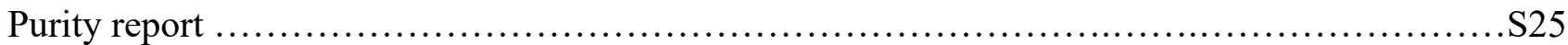


Table S1: Summary of results from the SafetyScreen $87^{\mathrm{TM}}$ panel by Eurofins. No receptors or enzymes exhibited $\geq 50 \%$ binding to PW507 by binding or enzymatic assays at $1 \mu \mathrm{M}$.

\begin{tabular}{|c|c|c|c|}
\hline Target & Binding \% & Target & Binding \% \\
\hline Cholinesterase, Acetyl, ACES & -3 & Transporter, GABA & 7 \\
\hline Peptidase, Angiotensin Converting Enzyme & 1 & GABAA, Flunitrazepam, Central & -3 \\
\hline ATPase, $\mathrm{Na}+/ \mathrm{K}+$, Heart, Pig & -3 & GABAA, Ro-15-1788, Hippocampus & -5 \\
\hline Peptidase, CTSG (Cathepsin G) & 0 & GABAA, Chloride Channel, TBOB & -7 \\
\hline Cyclooxygenase COX-1 & 26 & GABAB1A & -4 \\
\hline Cyclooxygenase COX-2 & -3 & Glucocorticoid & -10 \\
\hline Monoamine Oxidase MAO-A & 2 & Glutamate, AMPA & -6 \\
\hline Monoamine Oxidase MAO-B & 7 & Glutamate, Kainate & -9 \\
\hline Phosphodiesterase PDE3 & -21 & Glutamate, NMDA, Agonism & -2 \\
\hline Phosphodiesterase PDE4D2 & 0 & Glutamate, NMDA, Glycine & -8 \\
\hline Protein Tyrosine Kinase, Insulin Receptor & 0 & Glutamate, NMDA, Phencyclidine & -6 \\
\hline Protein Tyrosine Kinase, LCK & 6 & Glutamate, NMDA, Polyamine & 3 \\
\hline Protein Serine/Threonine Kinase, PKC, Non-Selective & 4 & Glutamate, Metabotropic, mGlu5 & 3 \\
\hline Adenosine A1 & -5 & Glycine, Strychnine-Sensitive & -14 \\
\hline Adenosine A2A & -2 & Histamine $\mathrm{H} 1$ & 2 \\
\hline Transporter, Adenosine & -8 & Histamine $\mathrm{H} 2$ & -15 \\
\hline Adrenergic alpha1A & 2 & Chemokine CXCR2 (IL-8RB) & -1 \\
\hline Adrenergic alpha1B & -2 & Leukotriene, Cysteinyl CysLT1 & 9 \\
\hline Adrenergic alpha1D & 2 & Melanocortin MC1 & 0 \\
\hline Adrenergic alpha2A & 2 & Melanocortin MC4 & 1 \\
\hline Adrenergic alpha2B & 5 & Muscarinic M1 & -1 \\
\hline Adrenergic beta1 & -20 & Muscarinic M2 & 8 \\
\hline Adrenergic beta2 & 1 & Muscarinic M3 & 5 \\
\hline Transporter, Norepinephrine (NET) & 16 & Muscarinic M4 & 7 \\
\hline Androgen (Testosterone) & -6 & Tachykinin NK1 & -2 \\
\hline Angiotensin AT1 & -6 & Neuropeptide Y Y1 & 0 \\
\hline Bradykinin B2 & 4 & Nicotinic Acetylcholine Alpha1, Bungarotoxin & -2 \\
\hline Calcium Channel L-Type, Benzothiazepine & -11 & Nicotinic Acetylcholine alpha3beta4 & -7 \\
\hline Calcium Channel L-Type, Dihydropyridine & -3 & Opiate delta1 (OP1, DOP) & -14 \\
\hline Calcium Channel L-Type, Phenylalkylamine & -2 & Opiate kappa (OP2, KOP) & -2 \\
\hline Calcium Channel N-Type & 4 & Opiate mu (OP3, MOP) & -2 \\
\hline Cannabinoid CB1 & 3 & Platelet Activating Factor (PAF) & -1 \\
\hline Cannabinoid CB2 & 4 & Potassium Channel [KATP] & 0 \\
\hline Chemokine CCR1 & -4 & Potassium Channel hERG & 8 \\
\hline Cholecystokinin CCK1 (CCKA) & -3 & PPARgamma & 1 \\
\hline Cholecystokinin CCK2 (CCKB) & 10 & Serotonin (5-Hydroxytryptamine) 5-HT1A & 19 \\
\hline Dopamine D1 & 18 & Serotonin (5-Hydroxytryptamine) 5-HT1B & 9 \\
\hline Dopamine D2L & -3 & Serotonin (5-Hydroxytryptamine) 5-HT2A & 10 \\
\hline Dopamine D2S & -14 & Serotonin (5-Hydroxytryptamine) 5-HT2B & 17 \\
\hline Transporter, Dopamine (DAT) & 19 & Serotonin (5-Hydroxytryptamine) 5-HT2C & 25 \\
\hline Endothelin ETA & -12 & Serotonin (5-Hydroxytryptamine) 5-HT3 & -1 \\
\hline Estrogen ERalpha & -1 & Transporter, Serotonin (5-Hydroxytryptamine) (SERT) & 14 \\
\hline Vasopressin V1A & -12 & Sodium Channel, Site 2 & 26 \\
\hline Progesterone PR-B & -2 & & \\
\hline
\end{tabular}


${ }^{1} \mathrm{H}$ NMR (400 MHz, $\mathrm{CDCl}_{3}$ ) spectra of 3 and 4.

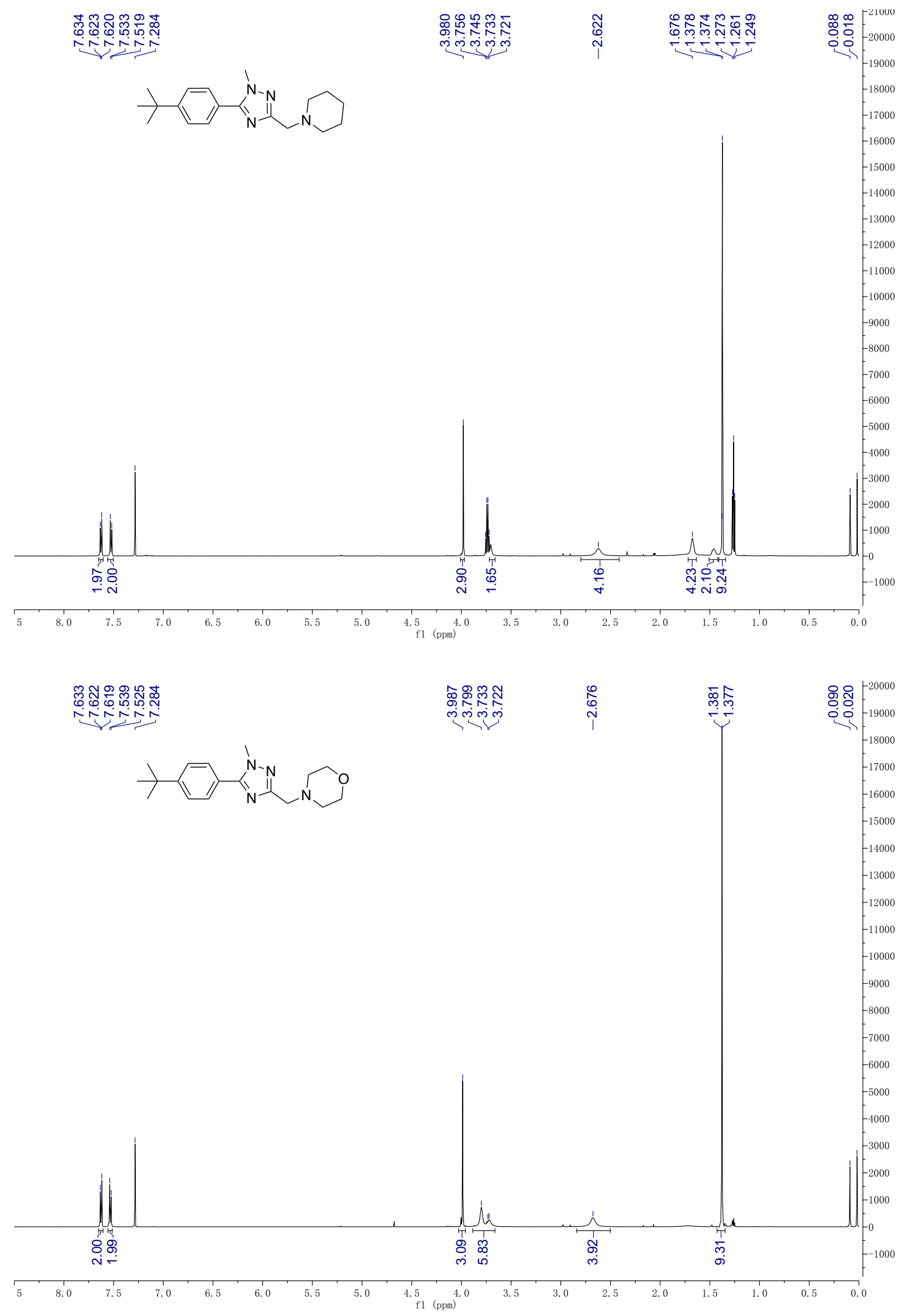


${ }^{1} \mathrm{H}$ NMR (400 MHz, $\mathrm{CDCl}_{3}$ ) spectra of 5 and $\mathbf{6}$.
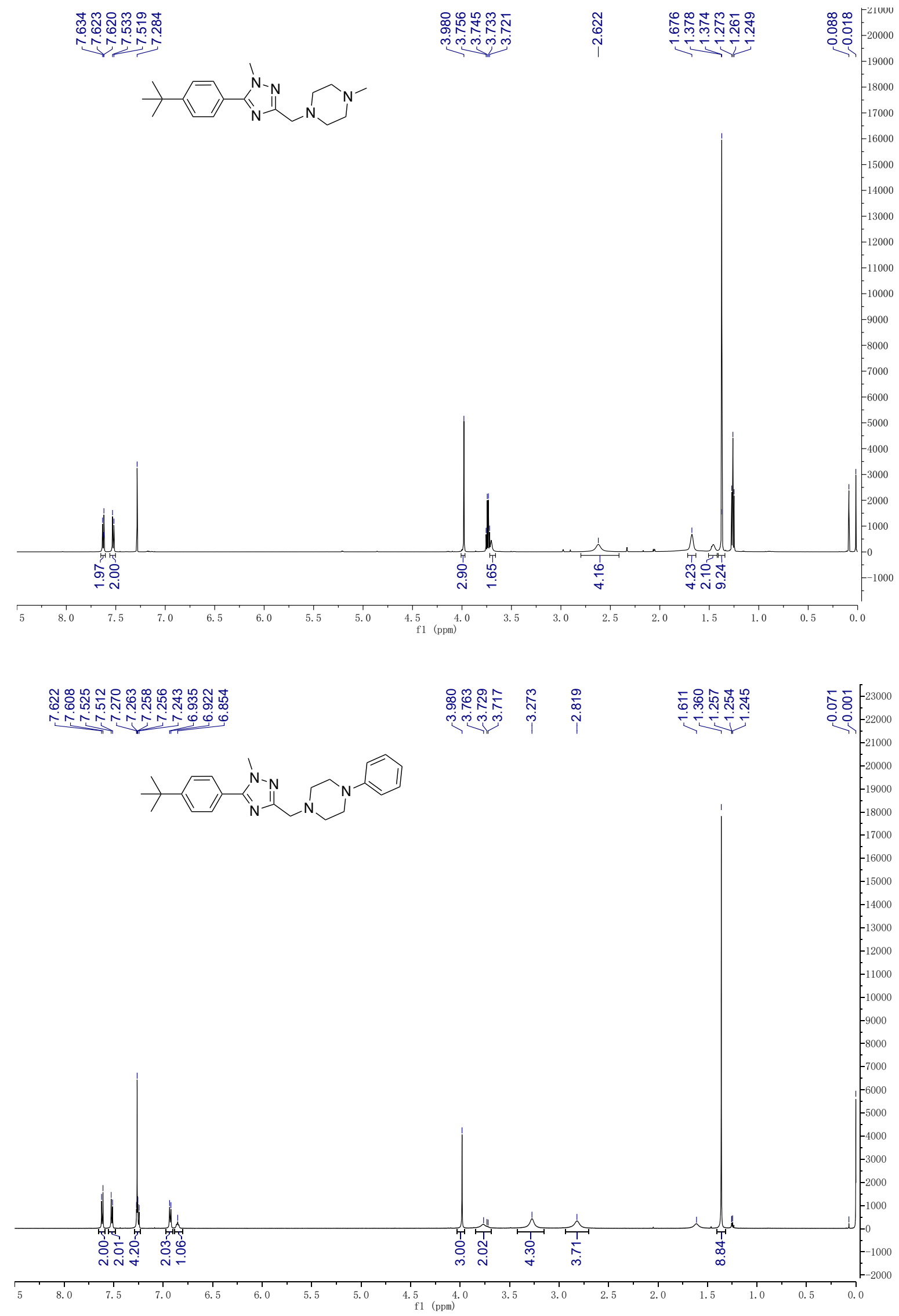
${ }^{1} \mathrm{H}$ NMR (400 MHz, $\mathrm{CDCl}_{3}$ ) spectra of 7 and 8.
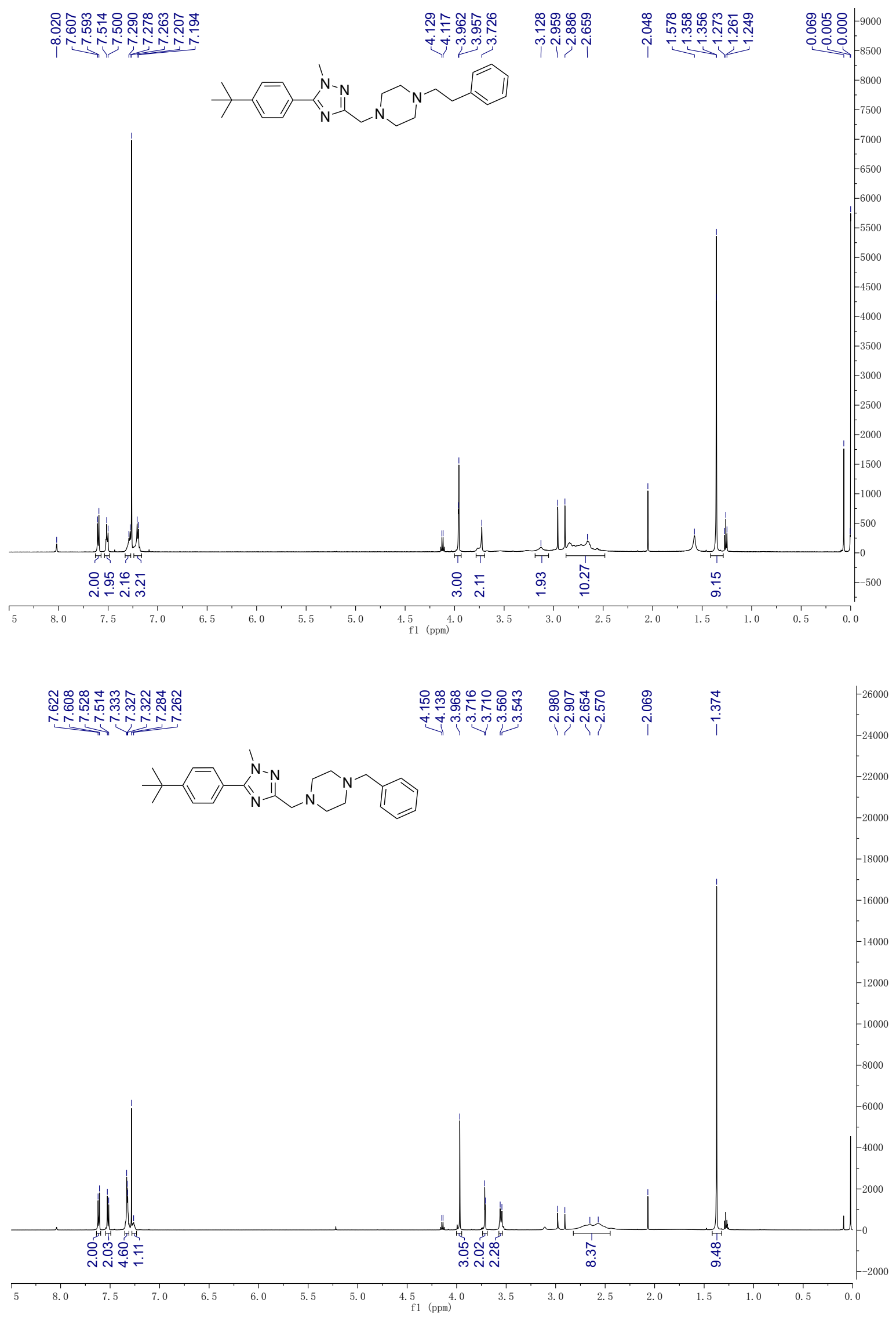
${ }^{1} \mathrm{H}$ NMR (400 MHz, $\mathrm{CDCl}_{3}$ ) spectra of 9 and $\mathbf{1 0}$.
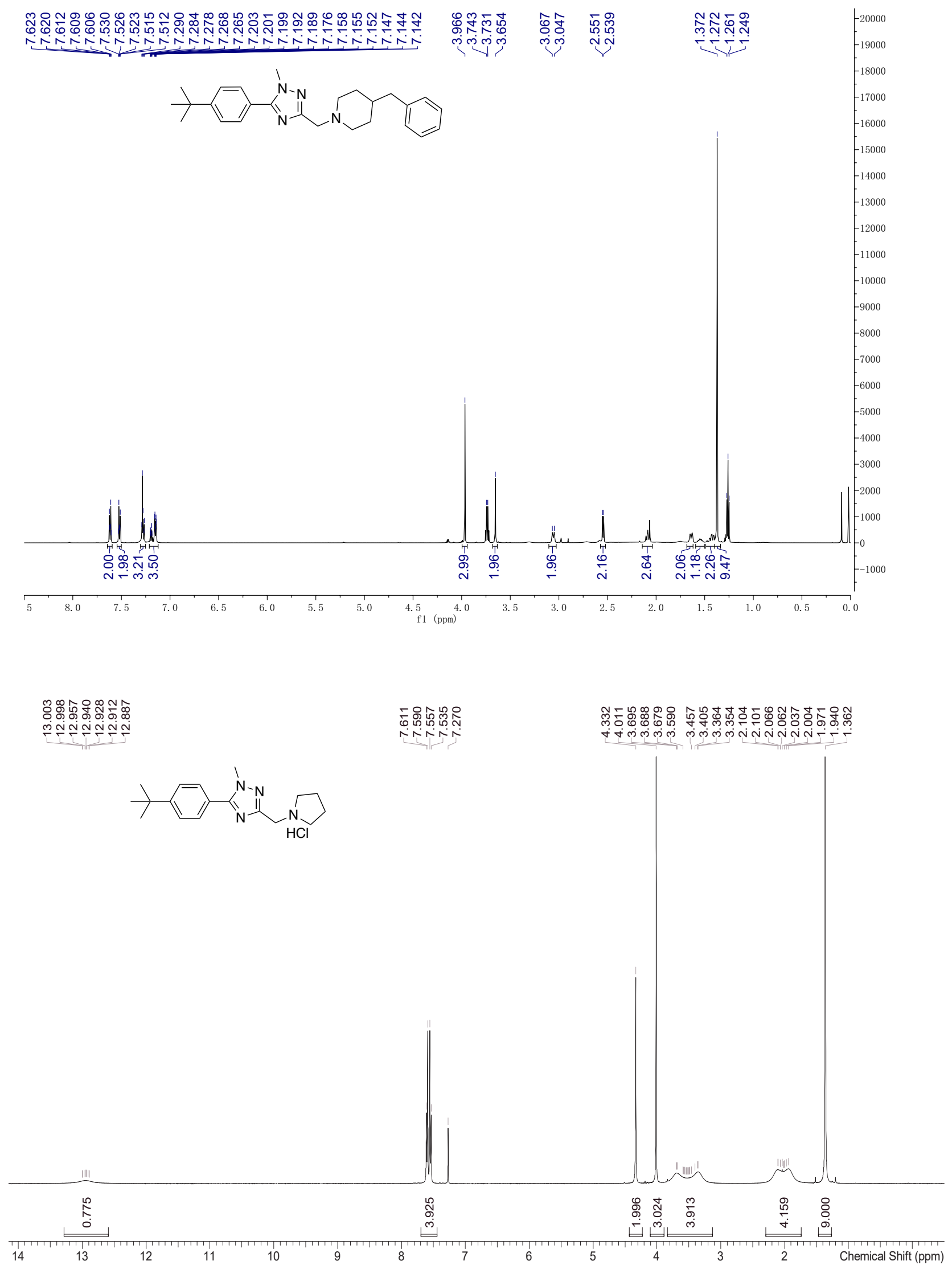
${ }^{1} \mathrm{H}$ NMR (400 MHz, $\mathrm{CDCl}_{3}$ ) spectra of 11 and 12.

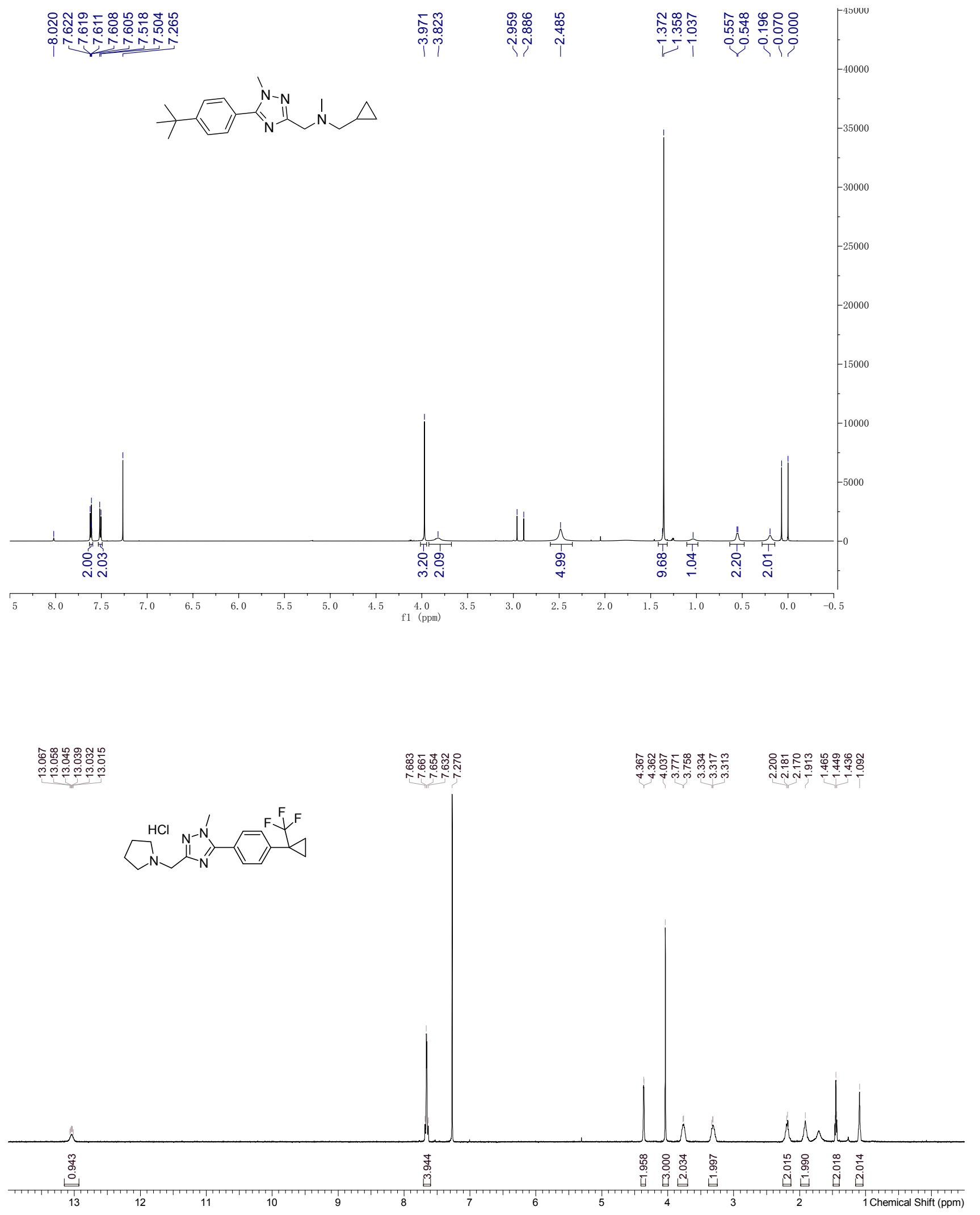


${ }^{1} \mathrm{H}$ NMR (400 MHz, $\mathrm{CDCl}_{3}$ ) of $\mathbf{1 3}$ and 14.
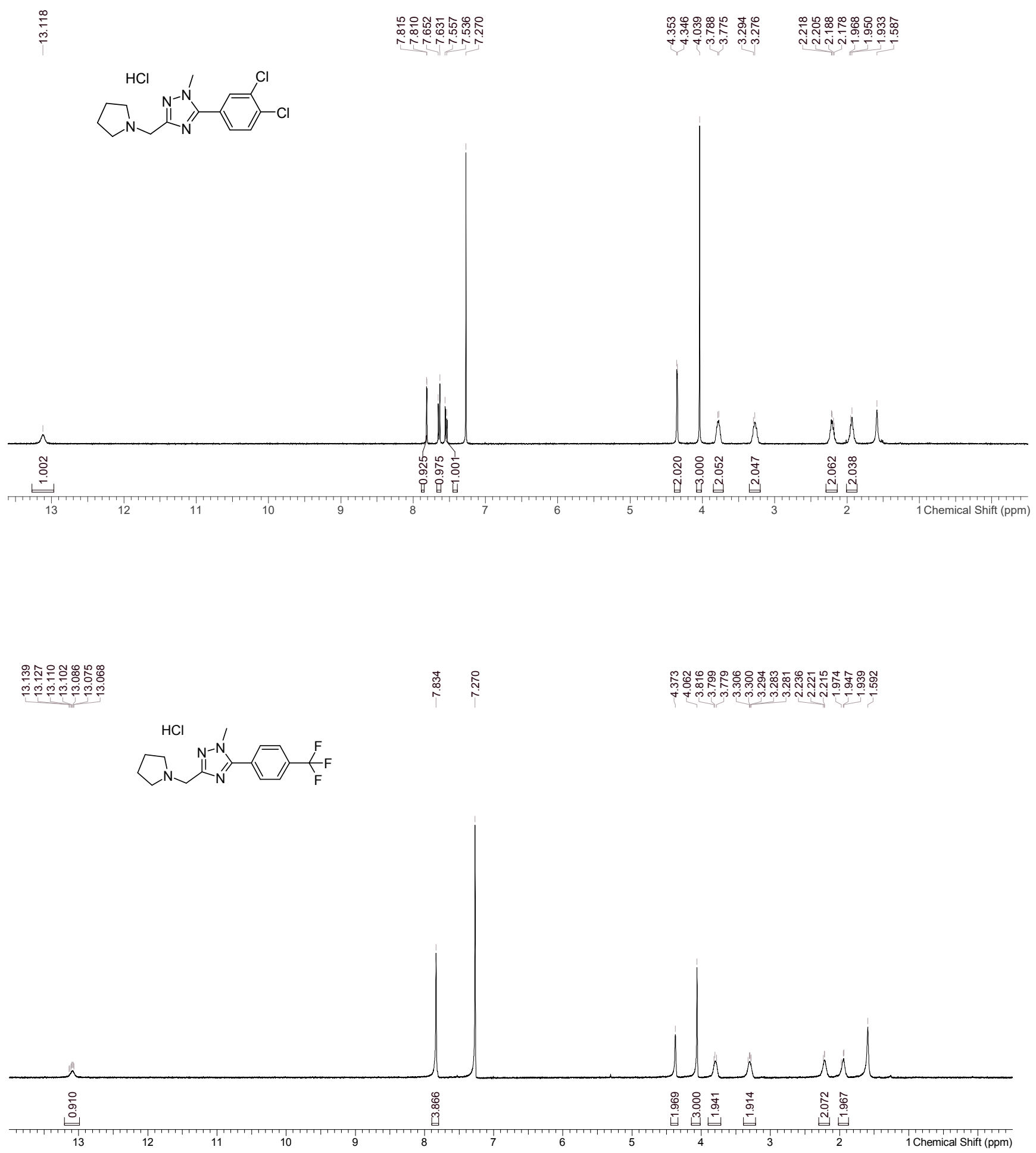
${ }^{1} \mathrm{H}$ NMR (400 MHz, $\left.\mathrm{CDCl}_{3}\right)$ of $\mathbf{1 5}$ and $\mathbf{1 6 .}$

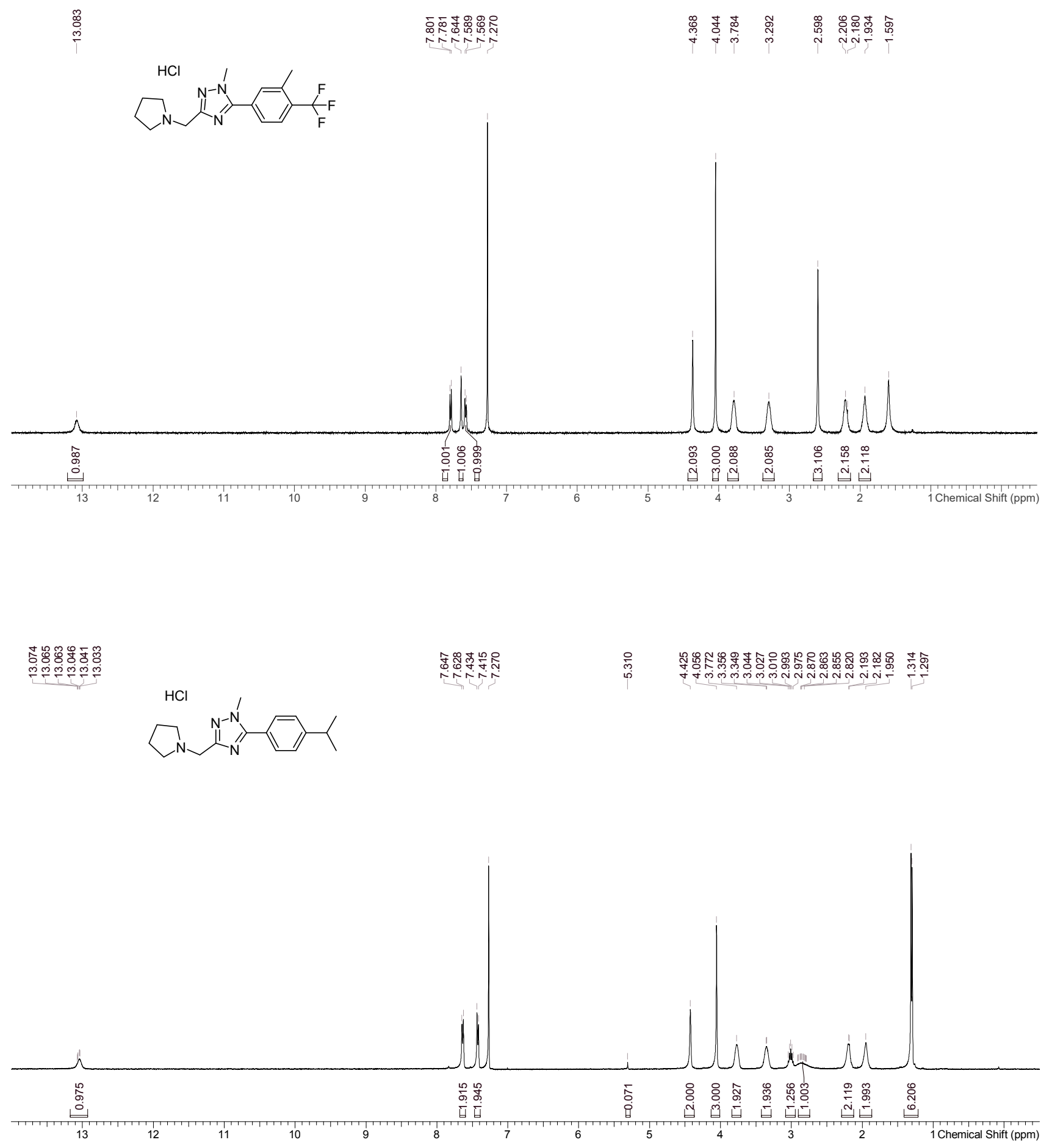


${ }^{1} \mathrm{H}$ NMR (400 MHz, $\mathrm{CDCl}_{3}$ ) spectra of $\mathbf{1 7}$ and $\mathbf{1 8 .}$

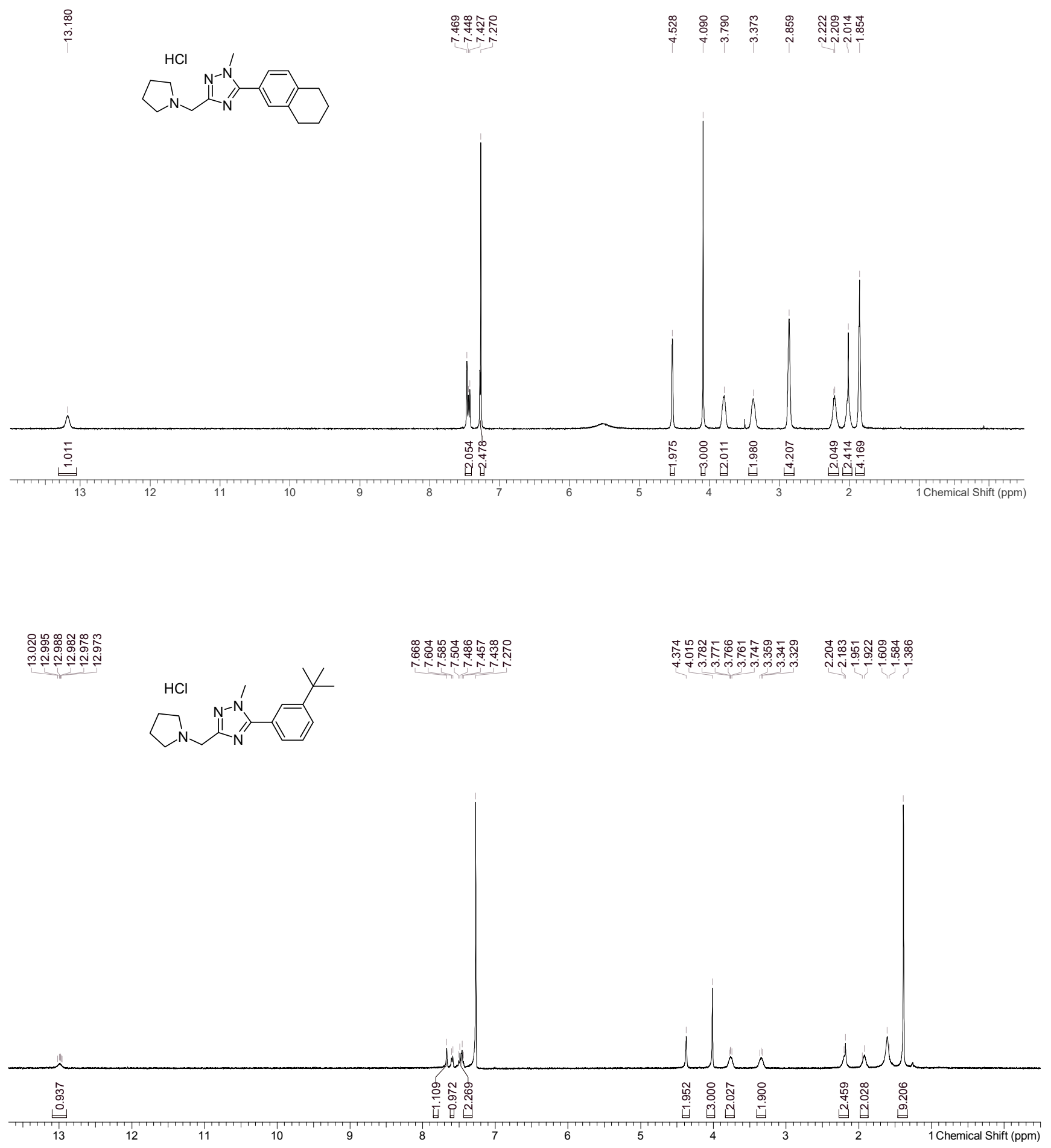


${ }^{1} \mathrm{H}$ NMR (400 MHz, $\mathrm{CDCl}_{3}$ ) of 19 and 20.
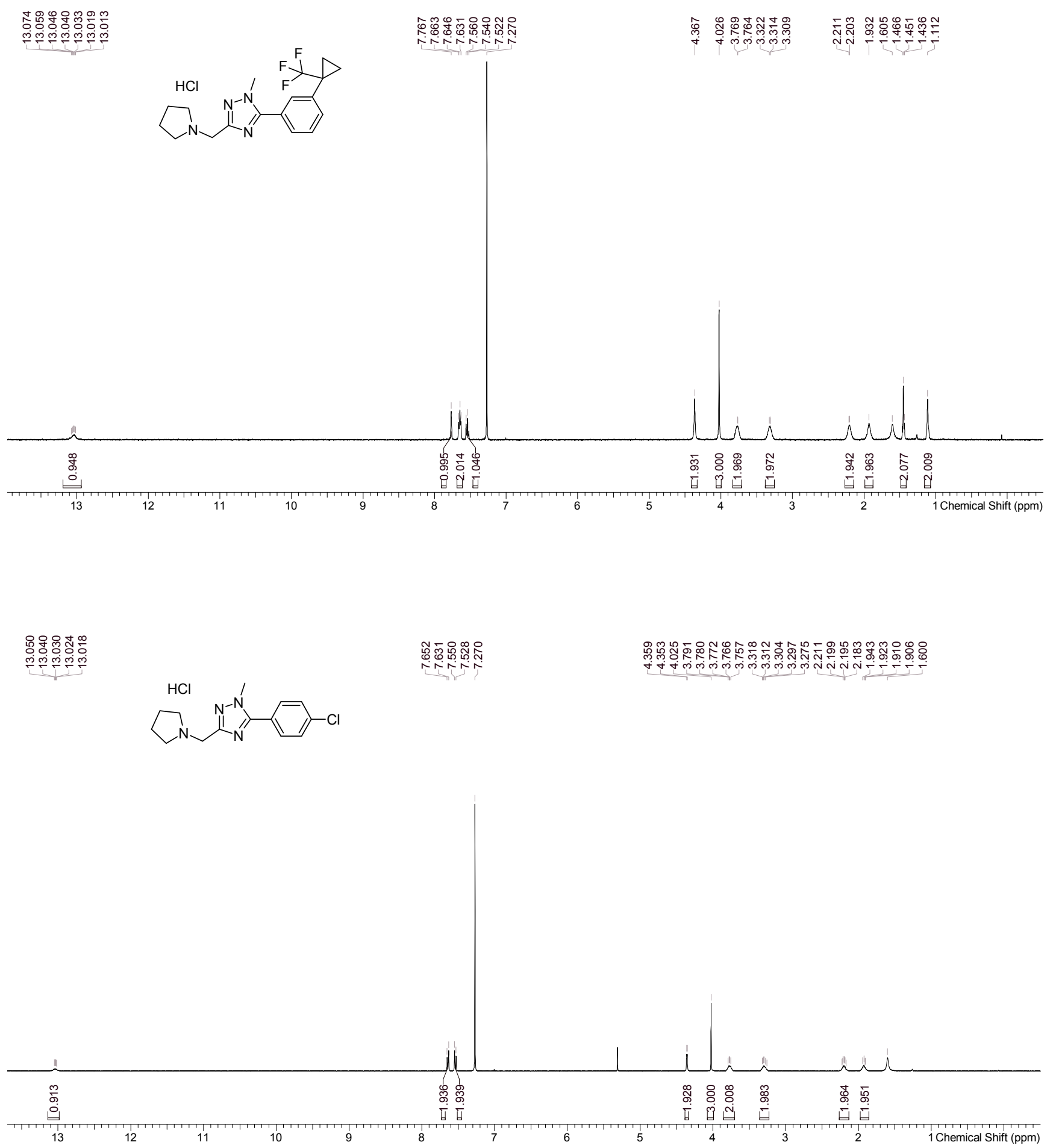
${ }^{1} \mathrm{H}$ NMR $\left(400 \mathrm{MHz}, \mathrm{CDCl}_{3}\right)$ spectra of 21 and 22.

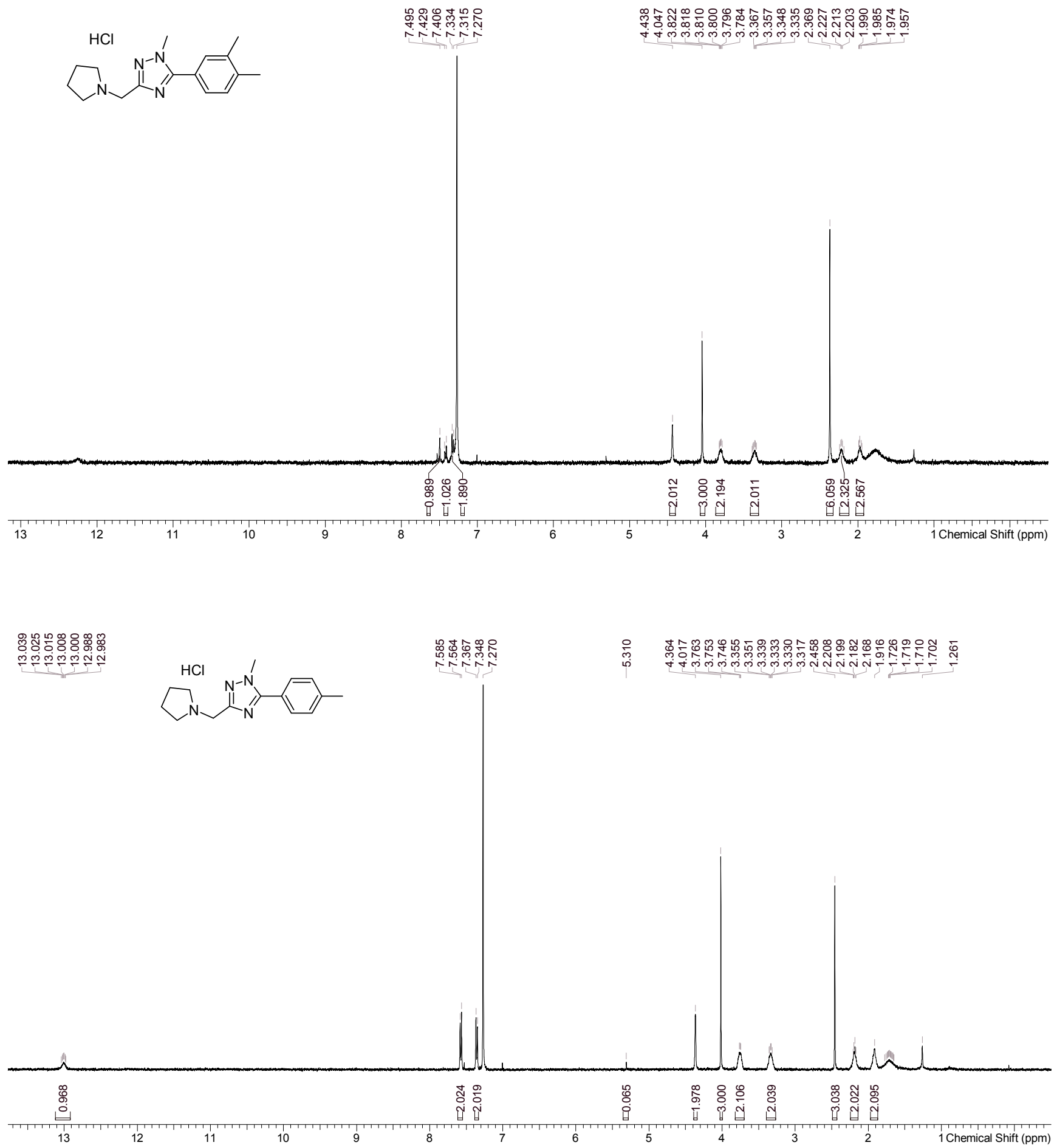


${ }^{1} \mathrm{H}$ NMR (400 MHz, $\mathrm{CDCl}_{3}$ ) spectra of $\mathbf{2 3}$ and 24.

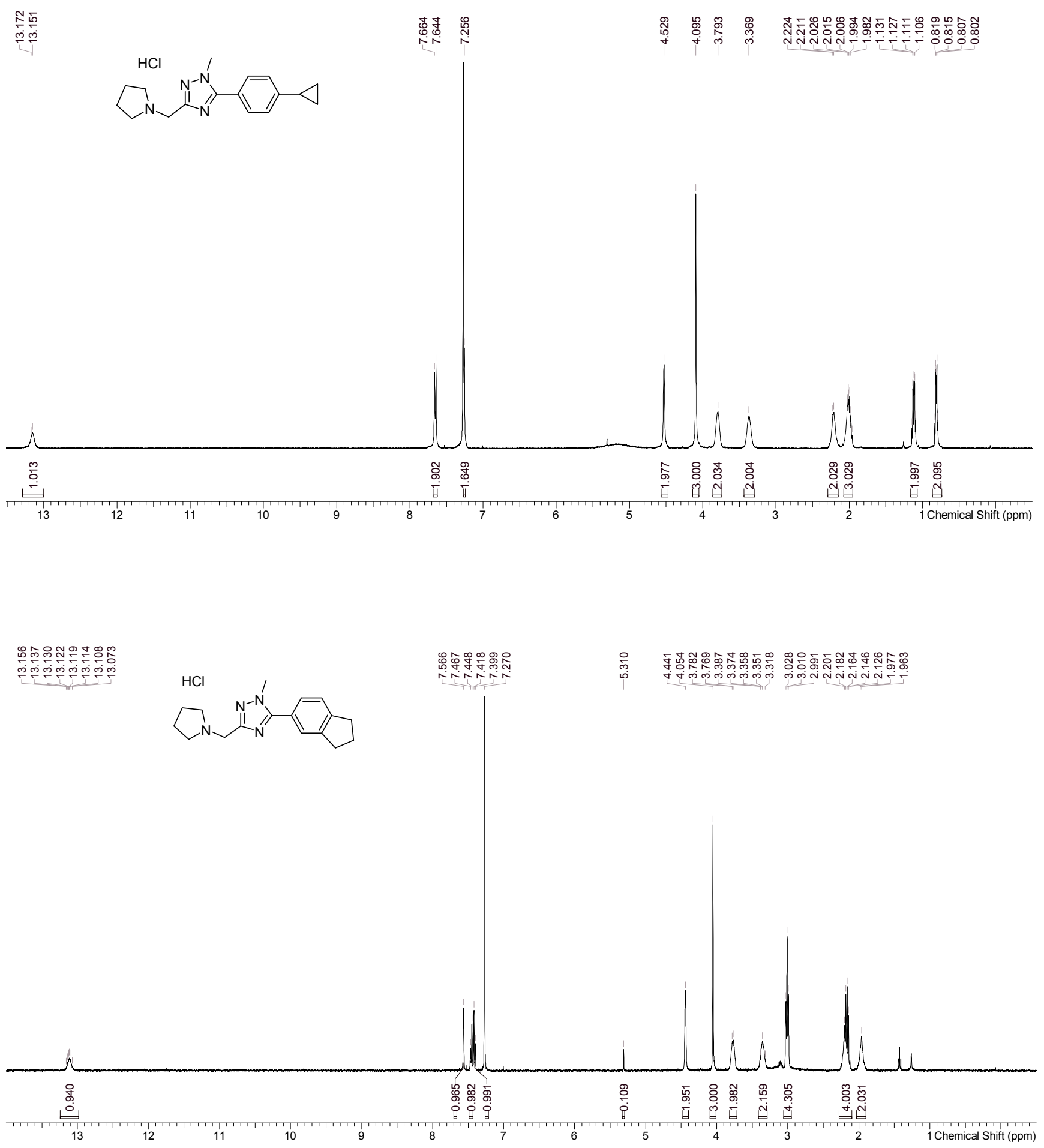


${ }^{1} \mathrm{H}$ NMR (400 MHz, $\mathrm{CDCl}_{3}$ ) spectra of $\mathbf{2 5}$ and $\mathbf{2 6}$.
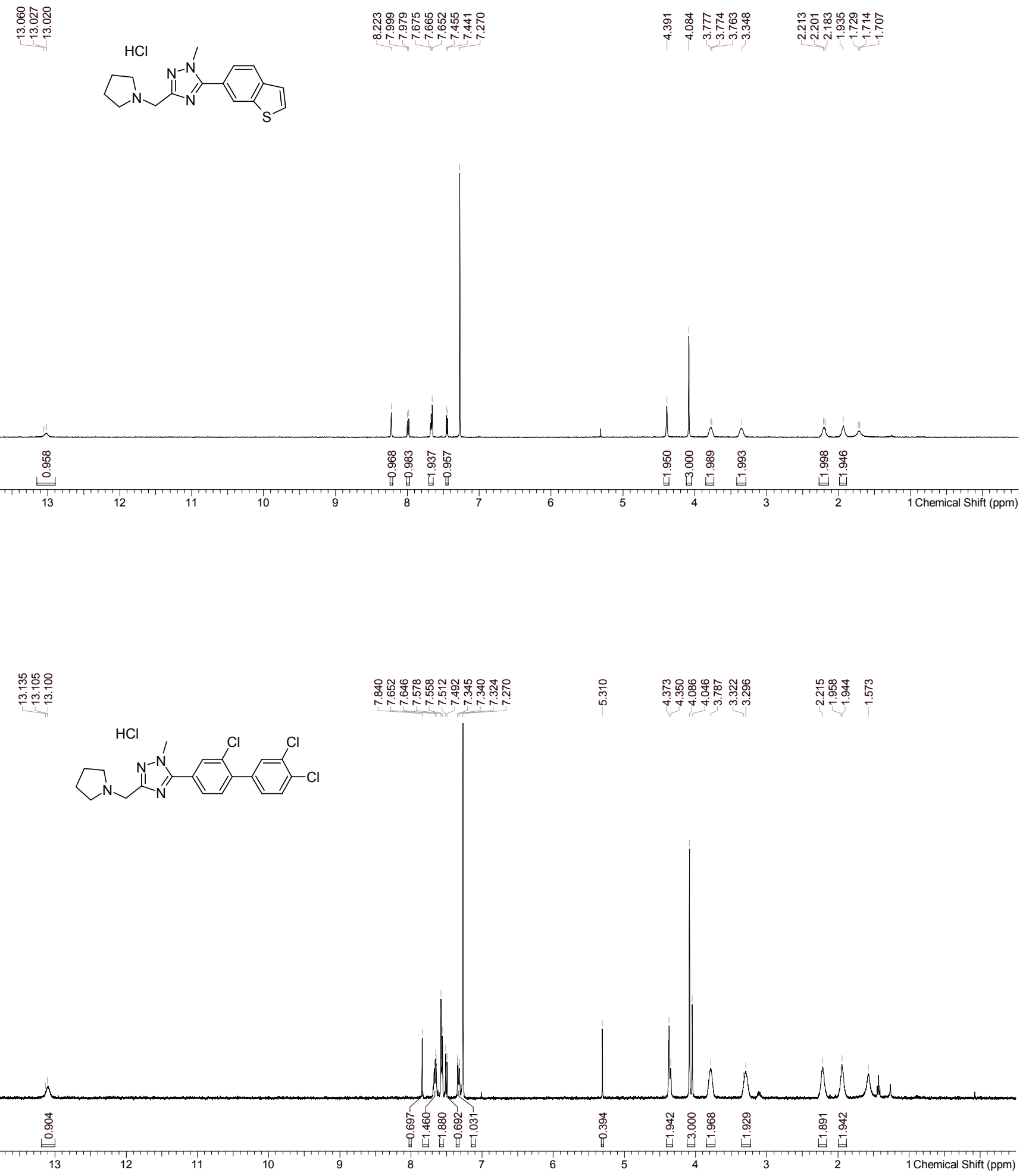
${ }^{1} \mathrm{H}$ NMR (400 MHz, $\mathrm{CDCl}_{3}$ ) spectra of 27 and 28.
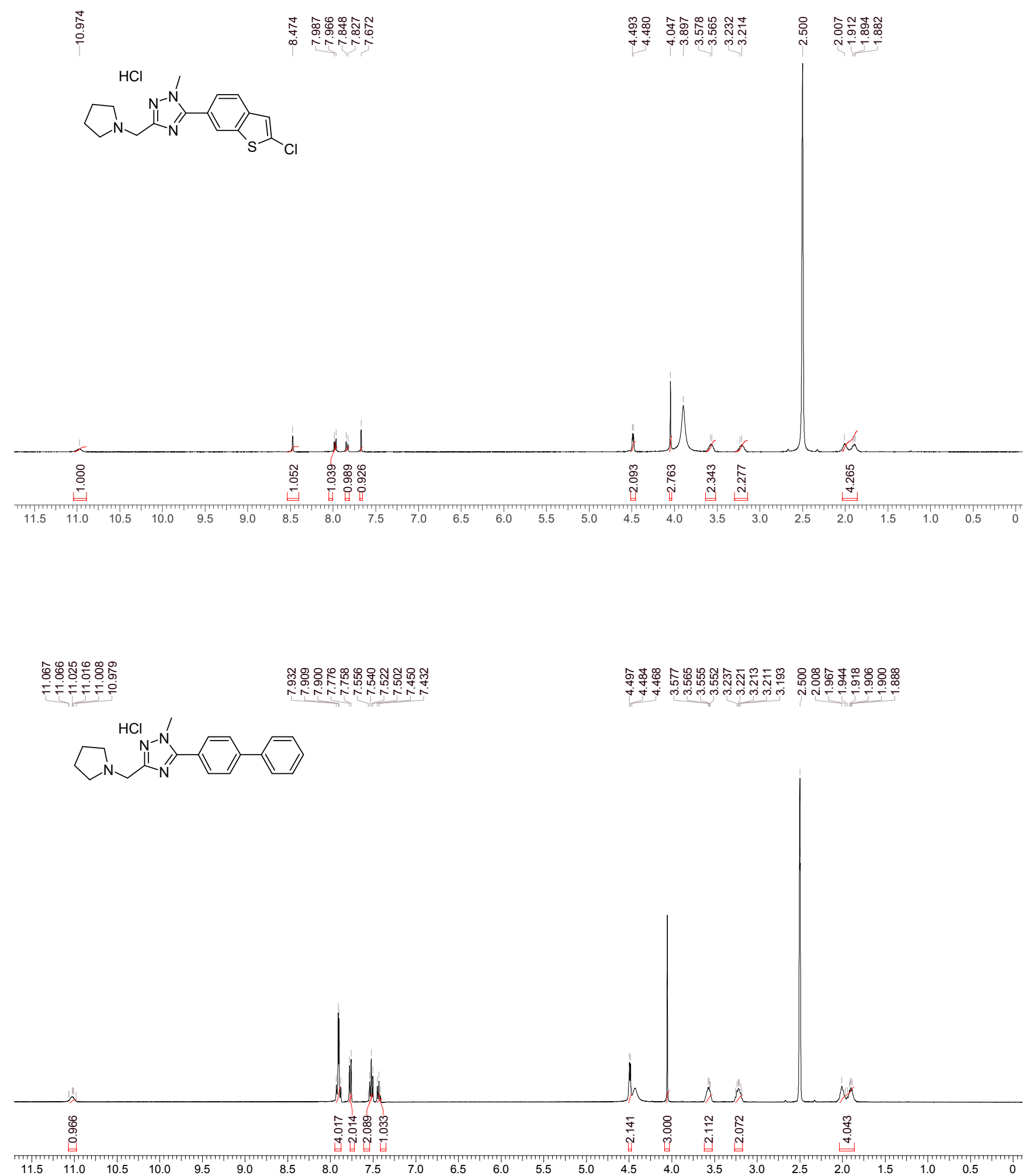
${ }^{1} \mathrm{H}$ NMR (400 MHz, $\mathrm{CDCl}_{3}$ ) spectra of 29 and $\mathbf{3 0}$.
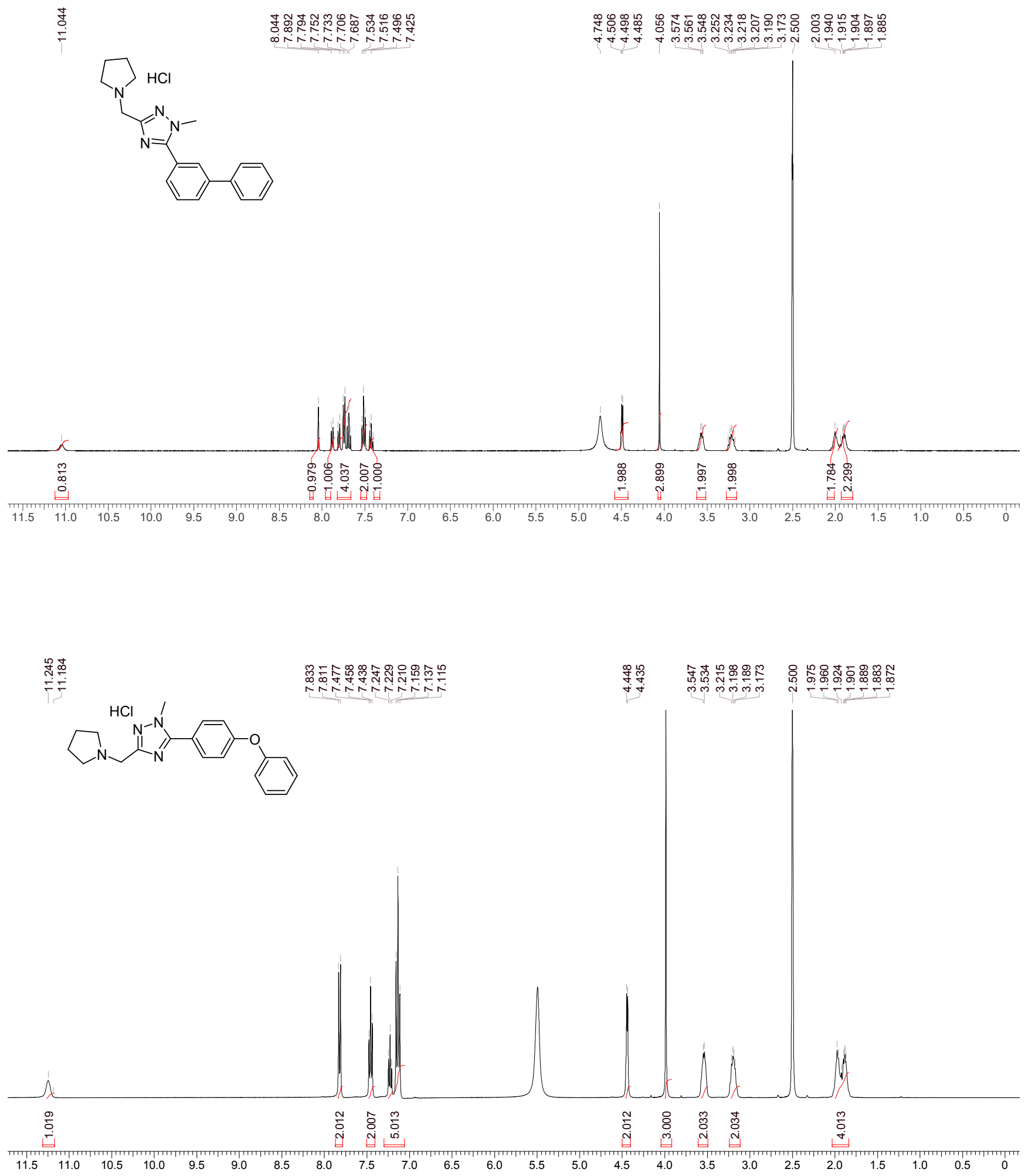
${ }^{1} \mathrm{H}$ NMR (400 MHz, $\mathrm{CDCl}_{3}$ ) spectra of $\mathbf{3 1}$ and $\mathbf{3 2}$.

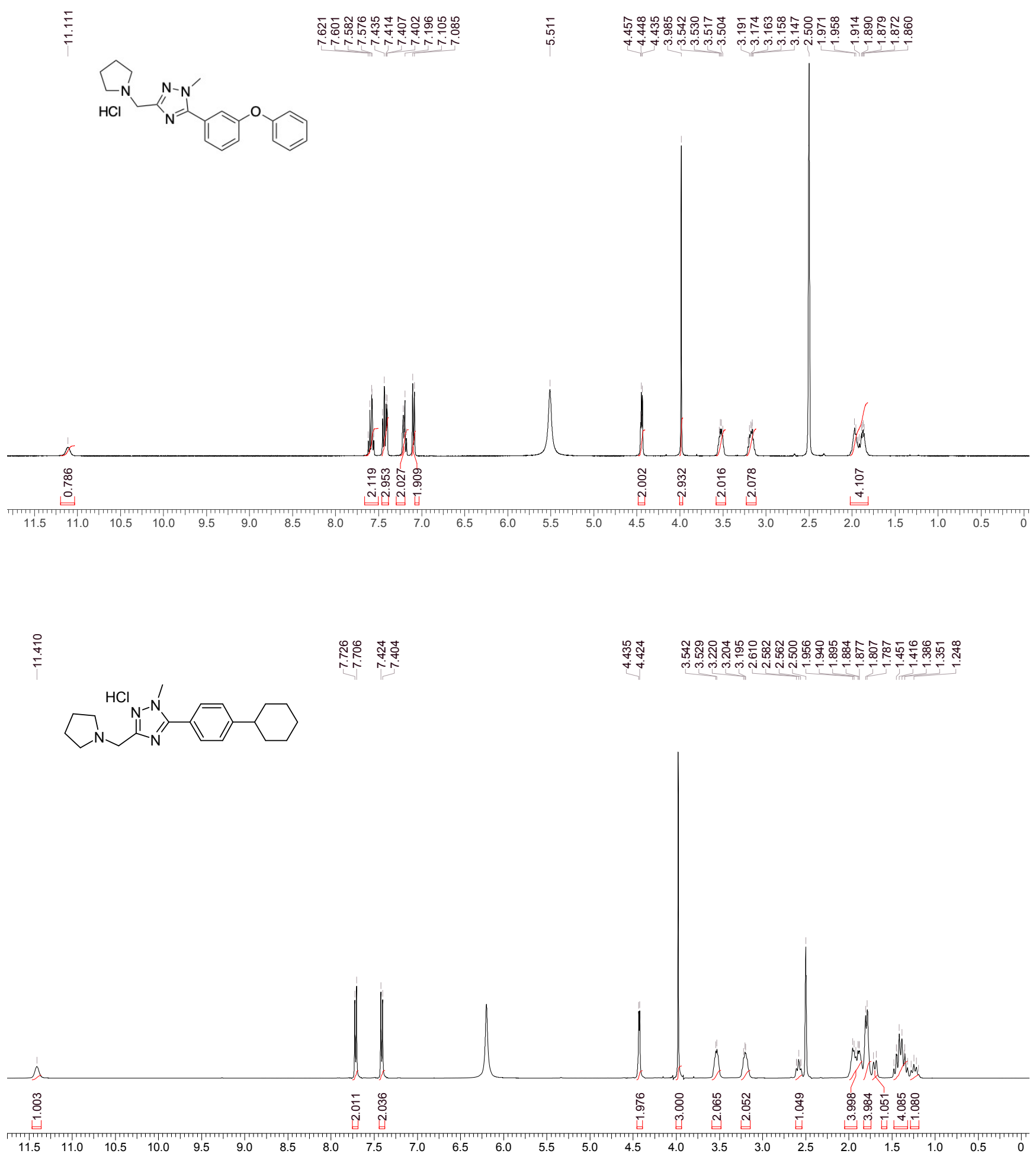


${ }^{1} \mathrm{H}$ NMR (400 MHz, $\mathrm{CDCl}_{3}$ ) spectra of $\mathbf{3 3}$ and $\mathbf{3 4}$.
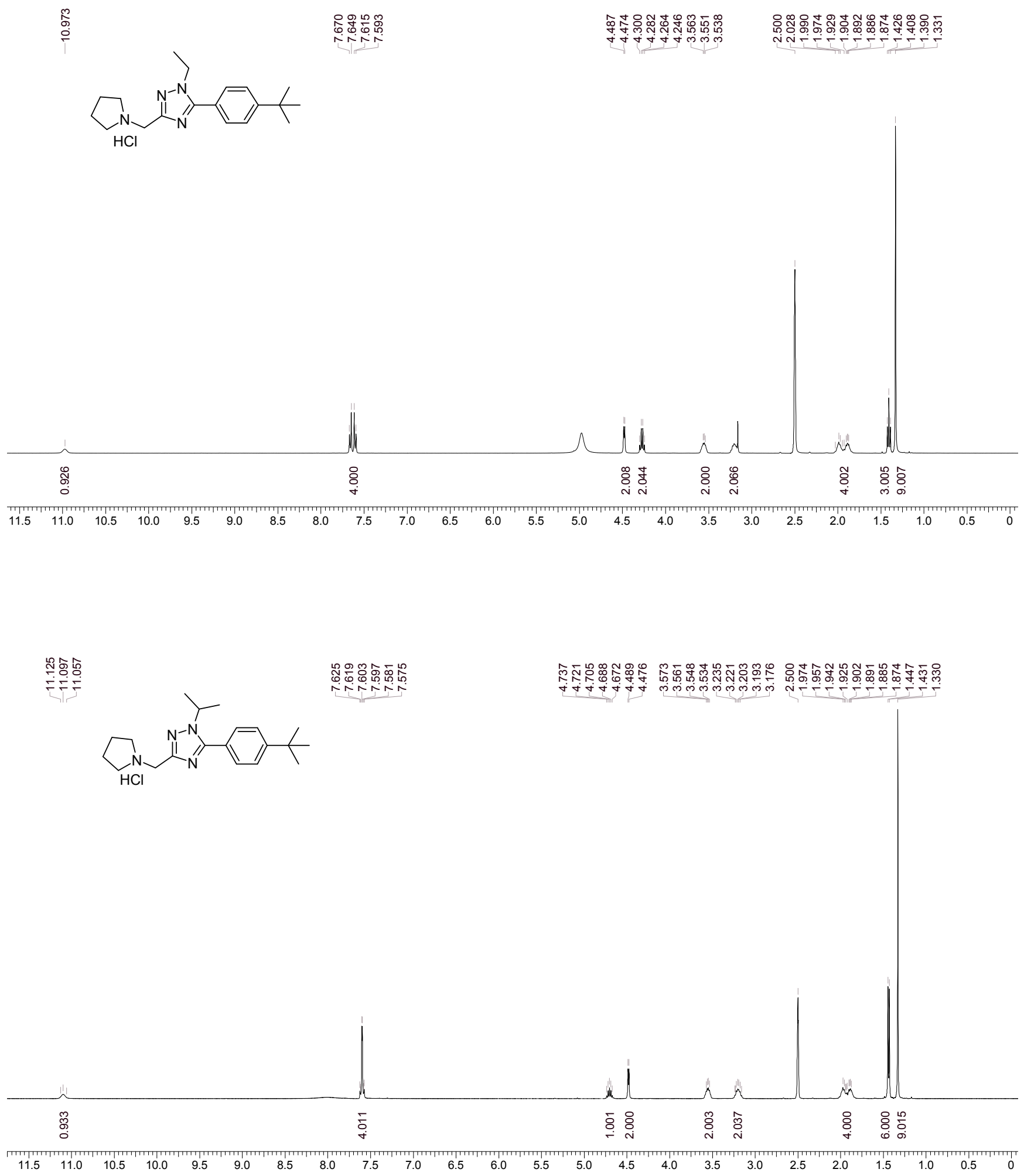
${ }^{1} \mathrm{H}$ NMR (400 MHz, $\left.\mathrm{CDCl}_{3}\right)$ spectra of $\mathbf{3 5}$.

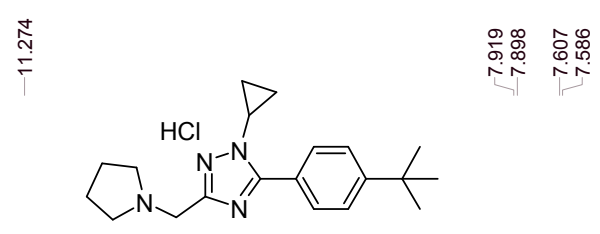

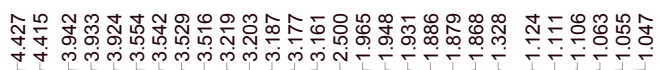

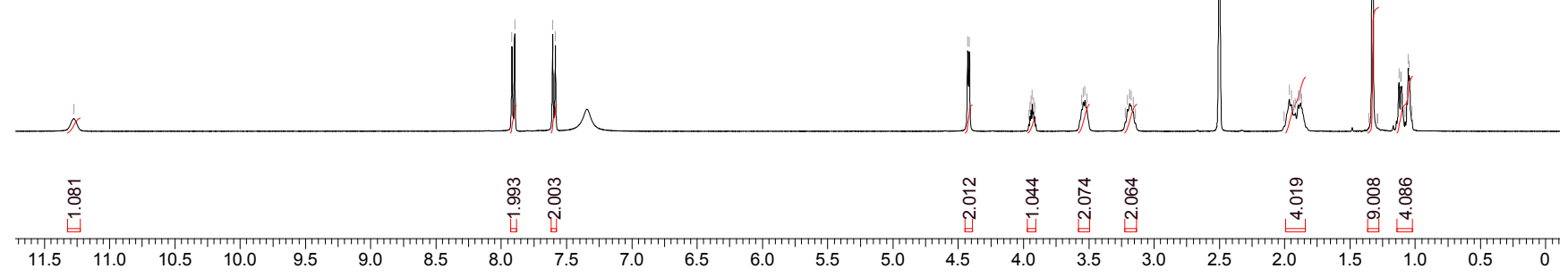

S20 
${ }^{13} \mathrm{C}$ NMR (101 MHz, DMSO-d 6 ) spectra of $\mathbf{1 0 .}$

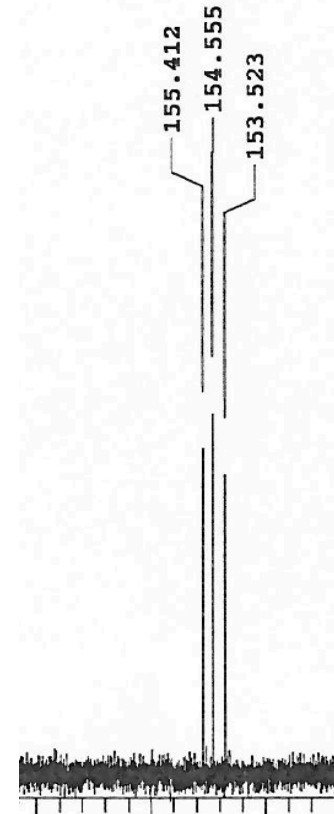

ปี

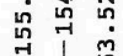

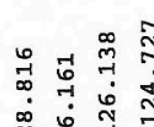

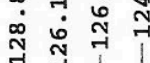
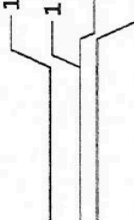

160

140

120

100

80

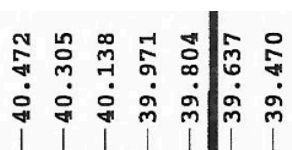

in

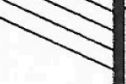

政

in

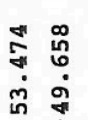

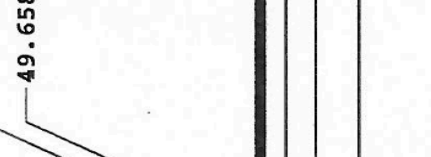


${ }^{13} \mathrm{C}$ NMR (101 MHz, $\left.\mathrm{CDCl}_{3}\right)$ spectra of 12.

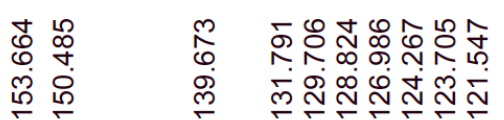

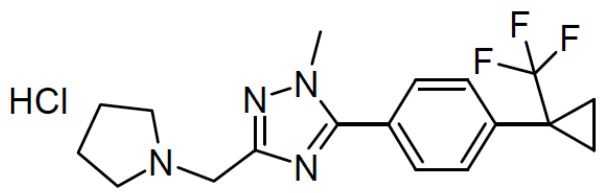

\section{등ㄷㅇㅇㅛ}

走令皇

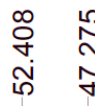

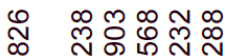

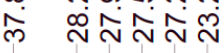

ڤ̊.

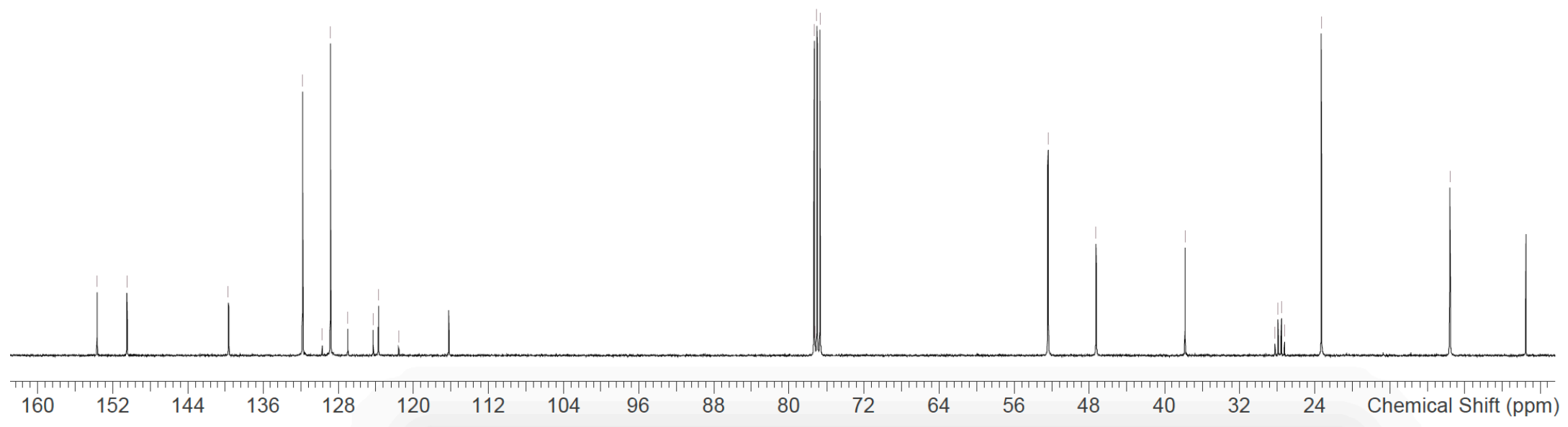


HRMS spectra for $\mathbf{1 0 .}$

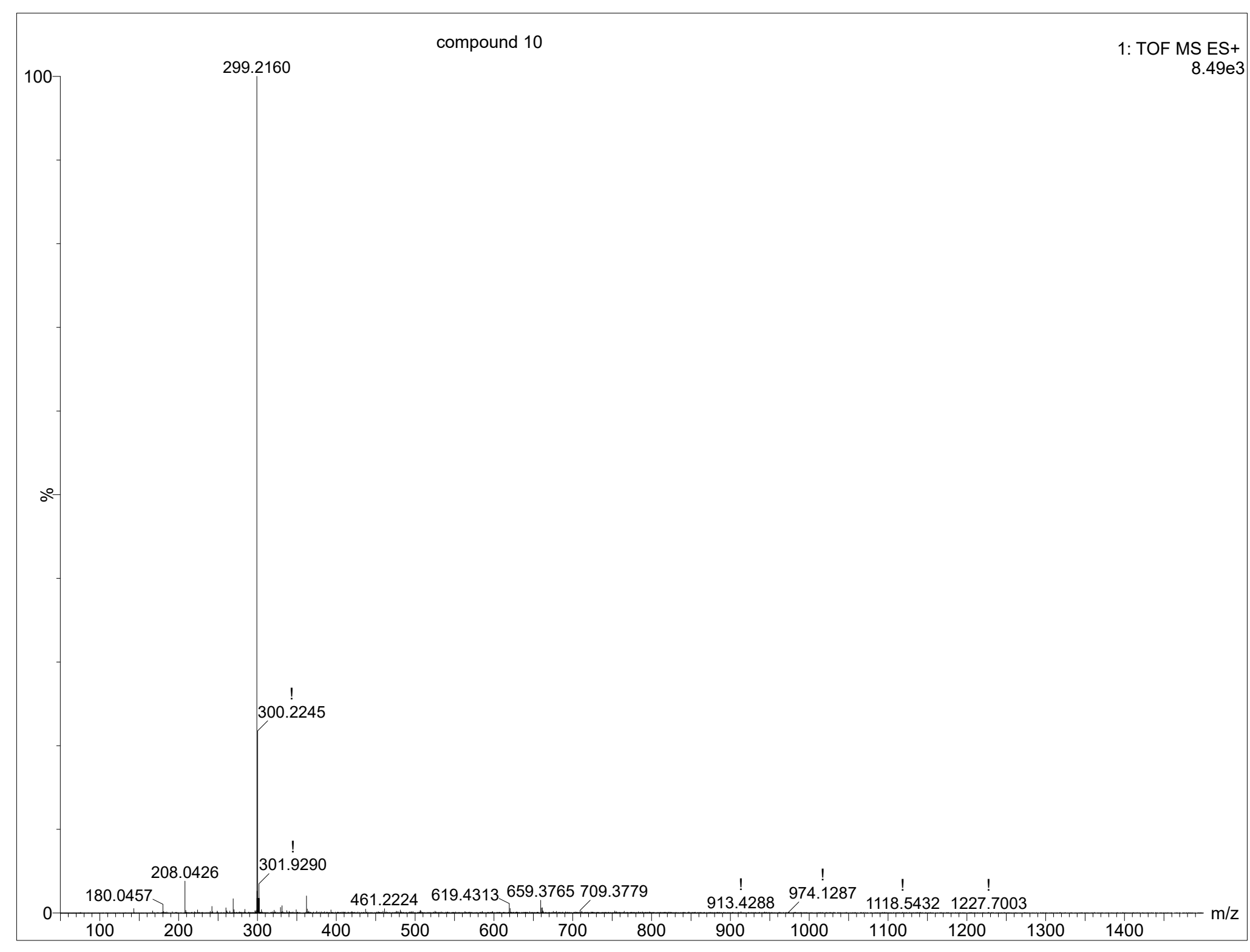


HRMS spectra for 12.

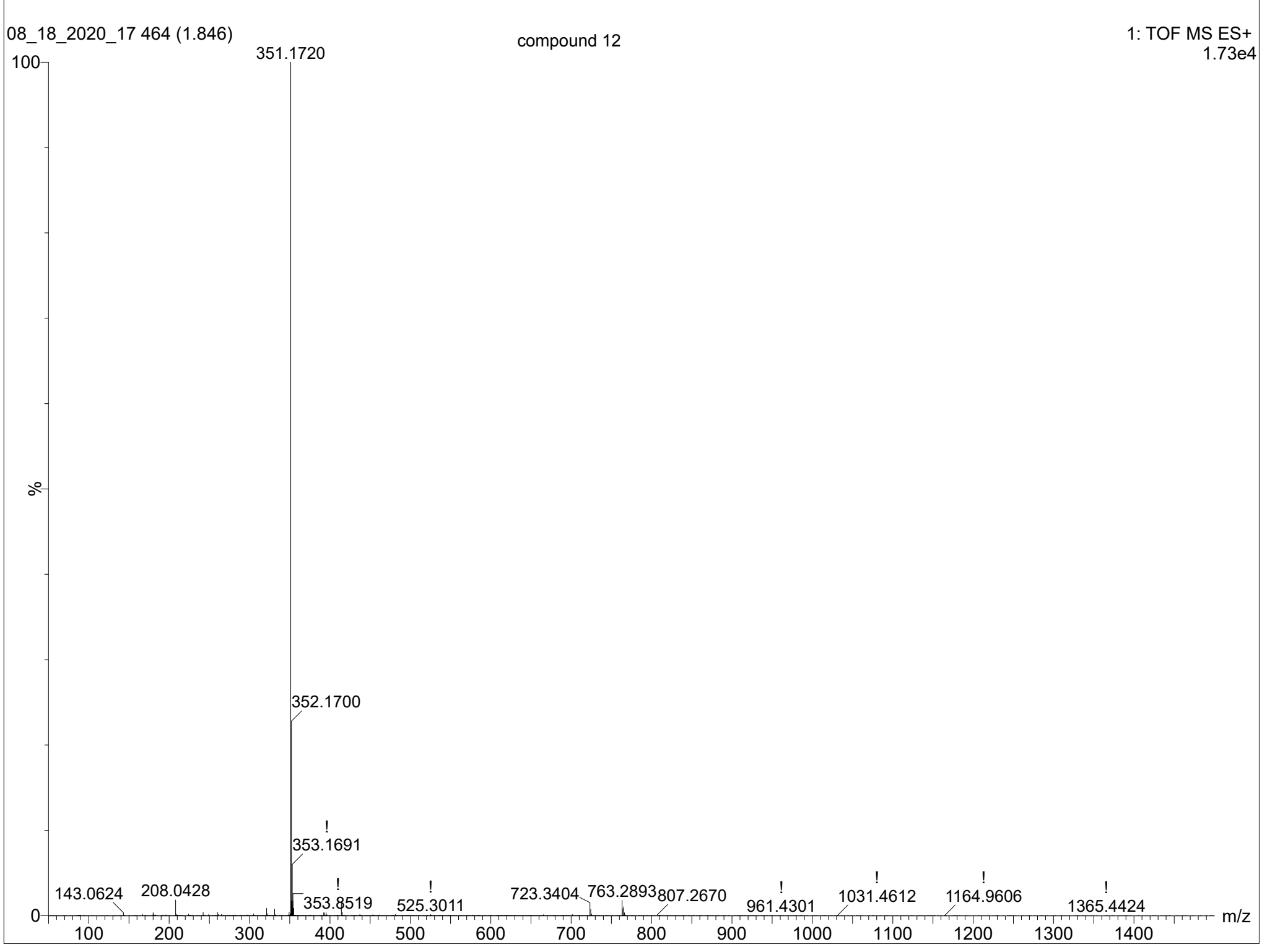




\section{Purity report for compound $\mathbf{1 0 .}$}

LCMS REPORT
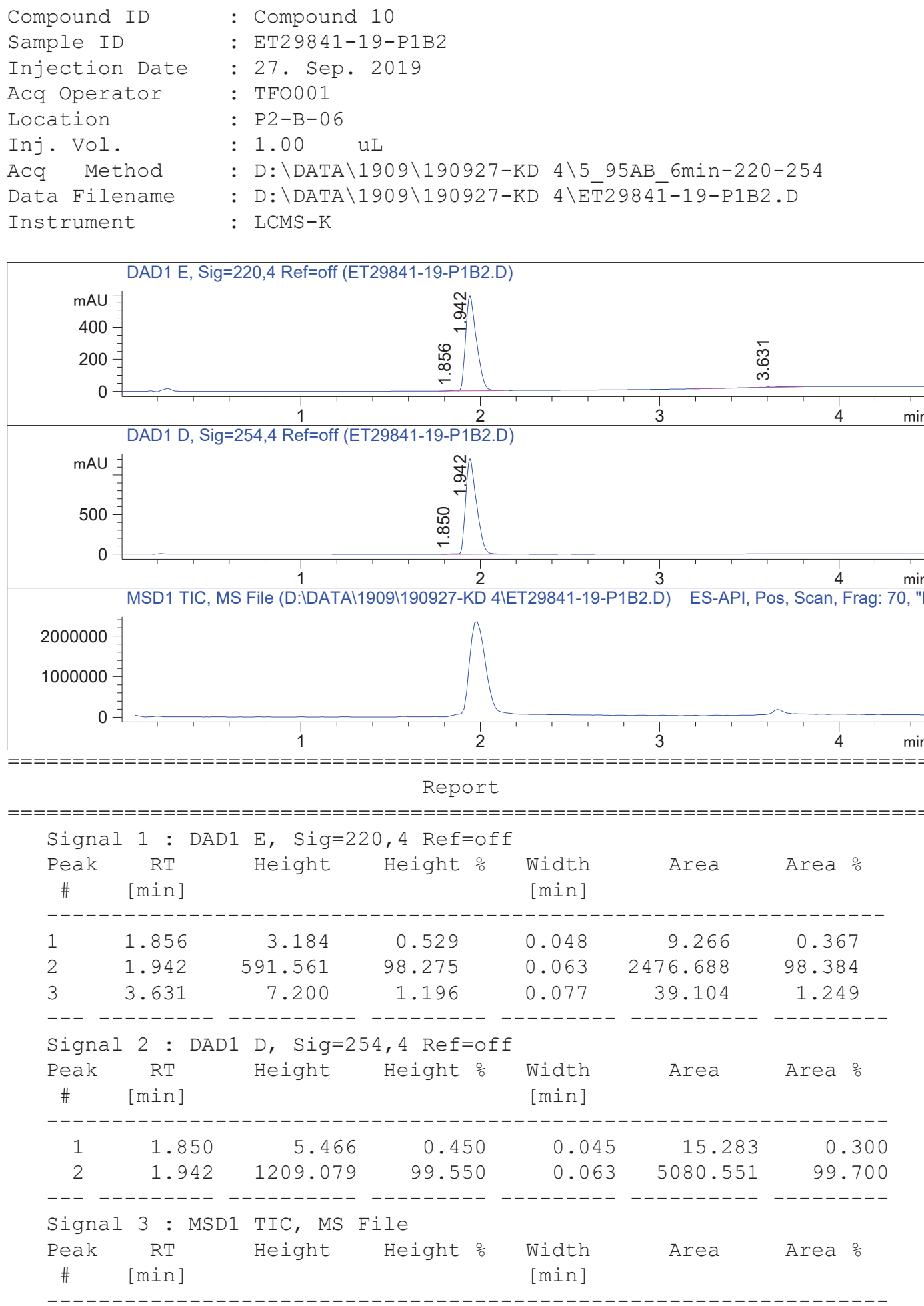